\title{
ENTRE BOATOS E VERDADES: A ORIENTAÇÃO SEXUAL DE CRIANÇAS ADOTADAS POR CASAIS HOMOSSEXUAIS
}

\author{
Josiane Peres Gonçalves ${ }^{1}$ \\ Fláubertt Odevanir Couto ${ }^{2}$ \\ Fábia da Silva Azevedo ${ }^{3}$
}

\begin{abstract}
The research, which aims to understand how the sexual development of children adopted / or who live as homoparental families, was carried out through questionnaires with 20 Pedagogy academics, 5 teachers and 3 psychologists from a municipality in the interior of Brazil. State of Mato Grosso do Sul. The results show that there are no differences in the development of the child living in a homoparental context, when compared to other children living in other family contexts, and the coexistence with new family arrangements causes children to grow understanding and respecting the differences and diversities that exist in society.
\end{abstract}

Keywords: Development of Sexuality. Children. Homoparental Families.

\section{Introdução}

A união conjugal entre pessoas do mesmo sexo tem se intensificado na atualidade e é alvo de polêmicas, preconceitos e estereótipos. Contudo, mesmo diante desse panorama, grande parte desses casais sente o desejo de constituir uma família, sentimento este, que também gerou muitas discussões entre as famílias brasileiras, que em sua grande parte são de núcleos heterossexuais.

As preocupações estão em torno da capacidade, de casais gays ou lésbicas, em criar os filhos, lhes oferecer afeto e ainda poder dar uma referência de gênero (masculino ou feminino), ou seja, numa família constituída por gays/lésbicas, quem desempenharia o papel de pai/mãe, tendo em vista que o senso comum crê que o menino/menina precisam de uma referência

\footnotetext{
${ }^{1}$ Universidade Federal de Mato Grosso do Sul, Campus de Naviraí (UFMS/CPNV).

${ }^{2}$ Universidade Federal da Grande Dourados

${ }^{3}$ Universidade Federal de Mato Grosso do Sul, Campus de Naviraí (UFMS/CPNV).
} 
masculina/feminina para poder construir sua identidade de gênero.

Foi nesse sentido, que a grande pergunta da nossa pesquisa urgiu da seguinte forma: Será que o modelo de família homoparental pode interferir na construção da identidade de gênero de uma criança? Visando encontrar possíveis respostas para tal indagação é que se justifica a realização do presente estudo que tem por objetivo compreender como se dá o desenvolvimento sexual de crianças adotadas/ou que convivem como famílias homoparentais.

A pesquisa foi realizada com alunas do $8^{\circ}$ semestre do curso de Pedagogia da Universidade Federal de Mato Grosso do Sul Campus de Naviraí MS, com 11 professores do respectivo curso e campus, e ainda com 06 psicólogas, sendo 05 de Naviraí e uma de Jaú, São Paulo. Os resultados são apresentados logo após a abordagem teórica, apresentada na sequência.

\section{Breve histórico da Homossexualidade}

As relações sexuais entre duas pessoas do mesmo sexo existem há muito tempo. Essa prática é mais antiga que a evolução do pensamento humano, independente do nome que esse ato receba, sua prática já vem de longas datas. De acordo com Pereira (2017) no século VII A.C, as práticas sexuais entre duas pessoas do mesmo sexo tinham função social e pedagógica, isso na Grécia Antiga. Esse relacionamento era visto de maneiras diferentes por duas cidades gregas, Esparta e Atenas.

De acordo com o autor, em Esparta as relações sexuais entre homens, era tida como parte do treinamento e disciplina militar, dessa forma, os mesmos eram incentivados a manterem sua vida sexual, tal ação era tida como um cuidado com o grupo. Contudo, em Atenas, a prática sexual recebia outro tipo de tipificação e estava ligada ao campo do conhecimento. Essa relação era bem aceita pela sociedade ateniense, tendo em vista que a prática se dava por um homem mais velho, o erastes, e um jovem mais novo, o eromenos.

Nessa égide, Pereira (2017) salienta que a relação sexual entre dois homens em Atenas ficava conhecida como paiderastia (o amor a meninos), essa relação tinha função de transmissão de conhecimento, portanto, essa relação 
era comum no processo de paidea (educação) dos meninos. Contudo, a autor desta que é

[...] necessário registrar a diferença da instituição pederastia da prática homossexual, uma tinha a função pedagógica e social que diverge totalmente do modelo da homossexualidade moderna, que é um tipo de relação afetiva. $\mathrm{Na}$ pederastia, os amantes deveriam seguir regras minuciosas de etiqueta para legitimar o papel social da relação e deixar longe qualquer dubiedade vinculada essa a prática (PEREIRA, 2017, p. 03).

Segundo ele, qualquer relação sexual entre dois homens que fugisse das regras, era considerada, ilícita e proibida. Se houvesse um caso contrário, era considerado como uma "[...] relação de uma maneira inferior, indigna, desprezível e desavergonhada [...]" (p. 04).

Nesse sentido, o que podemos compreender nesses trechos, refere-se ao surgimento do preconceito com relação aos atos da homossexualidade que eram praticados fora dos padrões estabelecidos, tal fato carrega marcas até a pós-modernidade. Além disso, nota-se também uma certa sobreposição de valores e submissão de poder, ou seja, é nítido nesse cenário que desde aquela época havia relações de poder que sobrepunham as pessoas.
Apresentados alguns aspectos históricos da homossexualidade na antiguidade até atualmente iremos abordar no próximo item a complexidade e a diversidade em relação ao desenvolvimento da sexualidade humana.

\section{Compreendendo a sexualidade humana}

Diante da necessidade de contribuir com a quebra de preconceitos atuais, torna-se importante, além de apresentar fatos históricos, refletir sobre como se dá a construção do sujeito, enquanto indivíduo sexual, ou seja, como se dá o desenvolvimento da sua sexualidade. Nessa perspectiva, a Coordenação de Políticas para a Diversidade Sexual do Estado de São Paulo (CoPoDiSe) considera que "A sexualidade humana é formada por uma múltipla combinação de fatores biológicos, psicológicos e sociais e é basicamente composta por três elementos: sexo biológico, orientação sexual e identidade de gênero" (SÃO PAULO, 2014, p. 10).

Compreendemos, desse modo, que a sexualidade é o resultado de muitas funções e elementos presentes no ser 
humano e não unicamente de uma variável. Esses fatores colaboram para que a sexualidade se desenvolva/mature nos indivíduos. Partindo desse pressuposto entendemos como sexo biológico o:

Conjunto de informações cromossômicas, órgãos genitais, capacidades reprodutivas $\mathrm{e}$ características fisiológicas secundárias que distinguem "machos" e "fêmeas". Há também pessoas que nascem com uma combinação diferente destes fatores, e que podem apresentar características de ambos os sexos. Essas pessoas são chamadas de Intersexos (SÃO PAULO, 2014, p. 10).

Nesse aspecto, entendemos por Orientação Sexual a "[...] atração afetiva e/ou sexual que uma pessoa manifesta em relação à outra, para quem se direciona, involuntariamente o desejo [...]", afirma a CoPoDiSe de São Paulo (2014, p. 10). Aqui gostaríamos de ressaltar que existem três tipos de orientação sexual, são elas:

[...] Heterossexual: Pessoa que se sente atraída afetiva e/ou sexualmente por pessoas do sexo/gênero oposto [...].

Homossexual (Gays e Lésbicas): Pessoa que se sente atraída afetiva e/ou sexualmente por pessoas do mesmo sexo/gênero [...]. Bissexual: Pessoa que se sente atraída afetiva e/ou sexualmente por pessoas de ambos os sexos/gêneros (SÃO PAULO, 2014, p. 10-11) (Grifo nosso).
Nota-se que nas palavras do autor a Orientação Sexual é um desejo involuntário, consequentemente, isso vem a ser como algo que foge ao controle da vontade, é automático, é inconsciente e espontâneo. Tal reflexão nos leva a questionar o termo "Opção Sexual", o considerando como inadequado $\mathrm{e}$ errôneo, pois não se trata de uma escolha, mas sim de algo natural.

Nessa lógica, é valido refletir sobre o conceito de identidade de gênero, que é entendido como a "[...] percepção íntima que uma pessoa tem de si como sendo do gênero masculino, feminino ou de alguma combinação dos dois, independente do sexo biológico. A identidade traduz o entendimento que a pessoa tem sobre ela mesma, como ela se descreve e deseja ser reconhecida", como afirma a CoPoDiSe de São Paulo (2014, p.13).

De acordo com a CoPoDiSe de São Paulo (2014) é possível notar uma nova terminologia associada a identidade, o "gênero". Tal nomenclatura foi criada em 1970, com o objetivo de distinguir a dimensão biológica da dimensão social. Deste modo, mesmo sabendo que a biologia divide a espécie humana em macho e 
fêmea, a maneira de ser homem e ser mulher é expressa pela cultura. Concluise que homem e mulher são produtos da realidade social e não diretamente de sua anatomia. Assim, observamos que ser homem e mulher, são apenas papéis de gênero, ou seja, é o comportamento social, determinado culturalmente e circunscrito historicamente, esperado por homens e mulheres.

Contudo, mesmo diante dessa perspectiva Papalia e Feldman (2013) afirmam que devemos levar em consideração as diversas perspectivas que abordam o desenvolvimento do gênero, são eles: a abordagem biológica, a abordagem evolucionista, a abordagem psicanalítica, a abordagem cognitiva (com subcategorias, chamadas de teoria cognitivo-desenvolvimental e teoria do esquema de gênero) e a abordagem da aprendizagem social.

Para os mesmos autores a primeira abordagem diz que as diferenças de gênero podem ser de base biológica. A segunda considera os papéis de gênero das crianças como uma preparação para o comportamento de acasalamento adulto. A terceira infere que a criança se identifica com o genitor do mesmo sexo, depois de ter desistido do desejo de possuir o genitor do sexo oposto.

A quarta abordagem sustenta que a identidade de gênero se desenvolve sobre a consciência que se tem do próprio gênero. Assim, a constância do gênero leva à aquisição de seus papéis. Dentro dessa mesma teoria acredita-se que a crianças categorizam as informações relacionadas a gênero, observando o que homens e mulheres fazem em sua cultura. A quinta abordagem indica que a criança aprende os papéis de gênero por meio da socialização. Os pais, os colegas, a mídia e a cultura influenciam a tipificação do gênero, afirmam Papalia e Feldman (2013, p. 292-294).

Ao compreendermos essas tipologias apresentadas pelos autores podemos observar que há diversos elementos que influenciam na construção da identidade de gênero e orientação sexual das crianças. Notamos ainda que os autores não as apresentam de forma que, alguma delas sejam sobrepostas entre si, o que nos faz pensar que elas podem ou não, em um dado momento exercer maior ação no desenvolvimento sexual da criança. 
Partindo desses pressupostos, buscaremos na sequência apresentar conceitos referentes as novas configurações familiares e discorrer a respeito da adoção de crianças por casais do mesmo sexo, ou seja, por casais de orientação homossexual e sobre as dificuldades que são enfrentadas por essas novas configurações familiares.

\section{Novas configurações familiares e a infância}

Segundo Passos (2005), as diferentes modalidades de famílias surgidas nos últimos tempos expressam transformações muito significativas na relação família-indivíduo-sociedade. A família de hoje impõe, no lugar da hegemonia dos papéis e dos lugares fixos, uma maior flexibilidade na constituição de posições e funções dos membros do grupo.

Nesse seguimento, cabe-nos refletir a realidade de casais brasileiros do mesmo sexo que tem enfrentado impasses no que diz respeito ao reconhecimento por lei de sua união estável como entidade familiar. Em 2013 e 2015 projetos de lei foram encaminhados para câmara dos deputados, a fim de incluir os casais homossexuais no Estatuto da Família, reconhecendo-os como família, porém este fato não se consolidou.

Posteriormente, o Conselho Nacional de Justiça (CNJ), na resolução $\mathrm{n}^{\circ} 175$ de 14 de maio de 2013, diz em seu Artigo $1^{\text {a }}$ que “[...] é vedada às autoridades competentes a recusa de habilitação, celebração de casamento civil ou de conversão de união estável em casamento entre pessoas de mesmo sexo" (Brasil, 2013).

Por esse ângulo, podemos observar o quanto a família homoparental tem tido resistência, no que diz respeito ao seu reconhecimento como instituição familiar. Todavia, o CNJ demonstrou um novo entendimento em relação aos casais homossexuais, atualmente o decreto completará sete anos.

De acordo com o Estatuto da Criança e do Adolescente (ECA), em seu Art. 25, compreende-se por “[...] família natural a comunidade formada pelos pais ou qualquer deles e seus descendentes" (BRASIL, 1990, p. 04). Nesse sentido, com relação a adoção de crianças, não há restrições específicas para casais homossexuais no ECA e 
como $o$ vemos na atualidade, 0 fenômeno da adoção por casais do mesmo sexo tem aumentado.

Dentre os critérios para adoção o Estatuto da Criança e do Adolescente, em seu Art. 42, parágrafo $1^{\circ}$ e $2^{\circ}$, estabelece: “[...] $§ 1^{\text {o }}$ Podem adotar os maiores de vinte e um anos, independentemente do estado civil [...]. § $2^{\circ}$ Para adoção conjunta, é indispensável que os adotantes sejam casados civilmente ou mantenham união estável, comprovada a estabilidade da família" (BRASIL, 1990, p. 06). E ainda em seu Art. 41 define que a "[...] adoção atribui a condição de filho ao adotado, com os mesmos direitos e deveres, inclusive sucessórios, desligando-o de qualquer vínculo com pais e parentes, salvo os impedimentos matrimoniais" (BRASIL, 1990, p. 06)

Ora observemos o que está disposto na lei. Se a união de pessoas do mesmo sexo tem reconhecimento civil, conforme a recomendação do $\mathrm{CNJ}$, ela atende o disposto Art. $42 \mathrm{em}$ seu $\S 2^{\circ}$ do ECA em relação a adoção conjunta e ao disposto no Art. 41, poderíamos afirmar que esta é uma família natural, pois se enquadra no entendimento do Art. 25.
Na concepção de Dias (2004) a Constituição Federal inciso II do Art. $5^{\circ}$ estabelece que sem limitação legal, não se pode negar o direito de crianças e adolescentes à adoção que lhes irá assegurar um lar, uma família, o afeto, independente da orientação sexual da família que quer adotar e de quem quer ser adotado, adoção nem sempre vai estar condicionado à preferência sexual ou à realidade familiar do adotante.

Nesse sentido, Dias (2004) afirma que o amor não vai se diferenciar somente pelo fato dos pais ou mães serem do mesmo sexo. Crê-se que aos poucos essa nova configuração familiar vai sendo aceita, em consequência disso, também vai ocorrendo uma aceitação da orientação sexual dos sujeitos que compõem ou não essa nova configuração. Porém a maior resistência em aceitar essas diferenças é o padrão de heteronormatividade.

Como dissemos anteriormente, essa dificuldade da aceitação de crianças serem adotadas por famílias homoparentais está embasada na afirmação de que a criança necessita de papéis de gênero, ou seja, caso a criança seja menino é necessário o papel masculino do pai para que ele seja 
homem, e caso for menina necessite do papel feminino da mãe para ser mulher. Além disso, há a crença de que se a criança for educada por casais homossexuais ela tem a possibilidade de desenvolver a mesma orientação sexual dos seus adotados, visto que, irá conviver nesse ambiente todos os dias.

Porém, de acordo com Dias (2004), as crianças que vivem em um lar homossexual poderão ser socialmente rejeitadas ou haverá prejuízo a sua inserção social, terão o seu desenvolvimento psicológico afetado, simplesmente pelo fato de advirem de uma outra configuração de família. Uma das possibilidade disso é que serão vítimas de discriminação devido a homofobia que impera na sociedade.

Nessas acepções, buscaremos no próximo tópico desenvolver aspectos sobre o desenvolvimento da personalidade/sexualidade da criança adotada por casais gays e abrangeremos tópicos relacionados a teorias do desenvolvimento.

\section{Entre boatos e verdades}

Alguns boatos em relação ao desenvolvimento de crianças adotadas por casais homossexuais tem mantido a discriminação e o preconceito para com esse novo arranjo familiar, muitas vezes essas atitudes estão permeadas de opiniões baseadas em senso comum, em argumentos falaciosos, em mitos que não são comprovados.

Nessa ótica, segundo Costa (et al. 2013, p. 791) existem atitudes negativas em relação as pessoas homossexuais. $\mathrm{O}$ autor indica que há três categorias de atitudes, são elas:

[...] (a) o medo ou repulsa por
pessoas homossexuais; (b) a
avaliação dos atos homossexuais
como desviantes ou patológicos; e
(c) as atitudes em relação aos
direitos das pessoas homossexuais,
categoria assente numa
perspectiva tradicional dos papéis
de gênero. (COSTA et al., 2013, p.
791).

Quando nos propomos a refletir essa realidade, nos deparamos com esses comportamentos negativos que se estabelecem como juízo sobre as pessoas homossexuais, é o que discorremos no início desse trabalho na parte histórica. Percebemos que na própria Grécia, qualquer atividade desligada da pederastia é tida como algo abominável.

Contudo, da mesma forma que há atitudes preconceituosas com as pessoas homossexuais, há com as famílias homoparentais. Assim, Costa 
(et al. 2013, p. 791) afirma que na maioria das vezes as pessoas com

[...] atitudes homonegativas são com frequência pessoas que mantém atitudes mais sexistas, com uma visão tradicional de família nuclear, acreditam que a homossexualidade é uma escolha do indivíduo, mantêm uma maior religiosidade e uma identificação política mais conservadora. (Grifo nosso).

Em Victória Clarke (2001 apud COSTA et al. 2013, p. 791), encontramos seis categorias de argumentos usados na comunicação social e no seio de alguns grupos de estudantes universitários que são contra a homoparentalidade e todos eles:

[...] (a) com base em crenças religiosas; (b) com base na impossibilidade biológica de reprodução; (c) com base no egoísmo dos pais/mães; (d) com base na falta de referências de gênero; (e) com base no desenvolvimento da orientação sexual; e (f) com base na vitimização e discriminação das crianças $[\ldots]$.

Segundo a autora, essas seis categorias são divididas em dois tipos de argumentos “[...] argumentos que reforçam a imoralidade de pais gays e mães lésbicas, e argumentos que sublinham os efeitos negativos de crescer numa família homoparental [...]" (Victória Clarke, 2001 apud COSTA et al. 2013, p.791).
Todos esses apontamentos nos levam as seguintes indagações: será que de fato a orientação homossexual dos responsáveis podem interferir no desenvolvimento da sexualidade dos filhos adotados? Mas se a vivência nesse espaço acarreta uma influência na orientação sexual dos filhos, por que há homossexuais advindos de famílias heterossexuais?

Constatamos em estudos realizados por Papalia e Feldman (2013) que cerca de 9 milhões de crianças nos Estados Unidos tenham pais homossexuais. Os estudos investigaram desenvolvimento dessas crianças no que diz respeito a saúde física e emocional, inteligência, adaptação, senso de identidade, julgamento moral e funcionamento social e sexual, porém não revelaram nenhuma preocupação especial.

Segundo as pesquisas de Papalia e Feldman (2013), não há nenhuma diferença concreta entre pais heterossexuais e homossexuais em termos de saúde emocional ou de aptidões e atitudes para a parentalidade, e onde há diferenças elas tendem a ser favoráveis aos pais homossexuais. Os autores afirmam ainda que não há 
nenhuma probabilidade de filhos advindos de famílias homoparentais, terem problemas em ficar confusos sobre seu próprio gênero ou até mesmo em se tornarem homossexuais.

Segundo os boatos, a falta de referência de gênero por parte de famílias homoparentais, faria com que as crianças não conseguissem desenvolverse normalmente, pois não teriam uma referência do que é homem e mulher. Contudo, Gato e Fontaine (2011, p. 84) tecem uma reflexão de que “[...] considerar a família heterossexual, com uma divisão tradicional de papéis, como o modelo desejável de parentalidade corresponde mais a um projeto ideológico do que a um fato cientificamente provado".

\section{Segundo Gato e Fontaine} (2011), a maior parte das investigações que buscaram conclusões a respeito das diferenças de gênero em termos de parentalidade não foram feitas para responder essa questão. O que nos faz entender não há comprovações suficientes que sustentem esses argumentos de que a criança precisa de uma figura materna e paterna, pois na maioria das vezes esses argumentos foram criados a partir de uma abordagem indutiva e indireta.

De modo profícuo a pesquisa dos autores trazem aspectos a respeito do desenvolvimento psicológico de crianças educadas em contexto homoparental. Seus estudos abordam três preocupações: o desenvolvimento psicossocial, as relações sociais e o desenvolvimento psicossexual. Com relação ao desenvolvimento psicossocial os autores afirmam que

$[\ldots]$ as avaliações do
comportamento da criança feitas
pelos pais não revelaram
diferenças substanciais entre as
famílias heteroparentais e as
famílias homoparentais. As
avaliações feitas pelos professores
também se revelaram consensuais
na observação de semelhanças
entre os dois grupos [...]. Os
resultados indicaram que estas
crianças apresentavam valores
médios ou médio-elevados em
termos da sua competência
académica, social e autoestima.
Situavam-se também fora das
pontuações indicativas da
presença de problemas clínicos em
temos da sua adaptação emocional
e comportamental. (GATO;
FONTAINE, 2011, p. 89).

No que diz respeito aos estudos voltados para as relações sociais de crianças que convivem com famílias homoparentais, os dados da pesquisa dos autores vão apontar que as relações sociais das crianças com seus pares e 
[...] sua eventual discriminação, os resultados não são unânimes. Alguns estudos indicaram que as crianças provenientes de famílias homoparentais se percepcionavam tão aceites e populares como os seus colegas provenientes de famílias heteroparentais. [...] verificaram que os jovens adultos que haviam crescido com mães lésbicas não se lembravam de ter sido mais alvo de discriminação pelos pares durante a infância e a adolescência; tampouco se lembravam de episódios de discriminação mais prolongados [...]. Apenas se verificou uma tendência (embora não significativa) para as crianças serem alvo de piadas sobre a sua própria sexualidade. (GATO; FONTAINE, 2011, p. 90).

Quanto ao desenvolvimento psicossexual das crianças adotas por casais homoparentais, segundo Gato e Fontaine (2011), três elementos merecem destaque especiais, que são: a orientação sexual, a identidade de gênero e os comportamentos ou papéis de gênero. Vejamos que

[...] à possibilidade de transmissão da orientação sexual, de acordo com $[\ldots] \quad 85 \%$ dos estudos publicados antes de 2003 verificaram uma proporção de filhos com orientação sexual homossexual semelhante à encontrada na população geral, isto é, entre 0 a $\mathbf{1 0 \%}$ [...]. A larga maioria das investigações também não encontrou provas do desenvolvimento de uma identidade de género contrária ao sexo biológico [...]. Quanto aos comportamentos/papéis de género, estes mostraram ser mais flexíveis, provavelmente devido ao seu carácter sociocultural.
Assim, embora tenham sido sobretudo identificadas semelhanças, alguns estudos evidenciaram que as filhas de mães lésbicas aderiam menos ao papel de género feminino tradicional do que as suas congéneres educadas em núcleos heteroparentais [...]. Tal como as raparigas, os rapazes educados por mães lésbicas comportavam-se de forma menos tradicional em algumas variáveis, apresentando, por exemplo, preferência por brincadeiras menos estereotipadas em termos de género [...] e registando níveis menos elevados de agressividade. (GATO; FONTAINE, 2011, p. 90). (Grifo nosso).

Portanto, perscrutado alguns estudos acerca do desenvolvimento de crianças adotadas por pessoas do mesmo sexo, notamos que a maioria dos problemas apontados são baseados em hipóteses não confirmadas cientificamente, mas embasadas em senso comum, uma vez que, os autores descortinam todas essas suposições. A seguir, iremos apresentar os aspectos metodológicos de nossa pesquisa e os dados mais relevantes de nossa pesquisa de campo.

\section{Aspectos metodológicos da pesquisa}

O presente estudo é uma pesquisa mista (quanti-qualitativa) de caráter descritivo e analítico, pois os dados levantados abrangem aspectos 
qualitativos e quantitativos. Nesse sentido, vale lembrar que, segundo Gil (2008, p. 28), ela “[...] têm como objetivo primordial a descrição das características de determinada população, fenômeno e/ou estabelecimento de relações entre variáveis". Dessa forma, caracteriza-se por pesquisa quantitativa aquela que:

[...] pelo emprego de quantificação tanto nas modalidades de coleta de informações quanto no tratamento delas por meio de técnicas estatísticas, desde as mais simples como percentual, média, desvio-padrão, às mais complexas como coeficiente de correlação, análise de regressão e etc (LAKATOS; MARCONI, 2011, p. 269).

Contudo, o método qualitativo, na contramão do método quantitativo, não se utiliza de instrumentos estatísticos, mas se preocupa em analisar e interpretar a realidade de maneira mais detalhada, buscando apresentar a complexidade do comportamento humano, possibilitando uma análise mais profunda dos conceitos, hábitos, comportamentos, atitudes e etc. (Lakatos; Marconi, 2011).

\section{Escolhemos o método} quantitativo para estabelecer informações estatísticas em relação a juízo dos entrevistados, no que diz respeito a saber quantos são de opinião a favor e opinião ao contrário a adoção de crianças por casais do mesmo sexo. Nesse mesmo ponto de vista iremos nos utilizar do método qualitativo para compreender e analisar as opiniões dos participantes acerca no que diz respeito às suas respostas.

O desenvolvimento teórico da pesquisa, buscamos investigar artigos e livros que tratassem do desenvolvimento da sexualidade das crianças adotadas por famílias homoparentais. Contudo, percebemos que há uma vasta gama de pesquisas internacionais relacionadas a esse tema, principalmente em países da Europa, como é o caso de Portugal, porém, no Brasil são raras as pesquisas sobre esse tema.

Em nossa pesquisa, nos valemos dos dados e estudos realizados por Portugal, tais estudos tratam da adoção por casais do mesmo sexo e o desenvolvimento das crianças nesse meio. Esse país tem suas bases na cultura judaico-cristã, tida por muitos sociólogos e historiados, como uma cultura reprodutora padrões de comportamento e valores conservadores. No entanto, notamos que se tem aumentado o número de constituições de famílias homoparentais. 
Nesse sentido, a pesquisa de campo se delimitou em três categorias de profissões para investigar: a primeira, em uma sala de acadêmicas do $8^{\circ}$ semestre do curso de Pedagogia, totalizando a quantidade de 27 alunas. A segunda, com um grupo de professores e professoras do respectivo curso (todos com nível de doutor e outros concluindo doutorado), totalizando a quantidade de 11 profissionais, sendo três (03) do gênero masculino e oito (08) do gênero feminino. A terceira com um grupo de seis (06) psicólogas, duas (02) especializadas na perspectiva humanista, três (03) na perspectiva comportamental e uma (01) na perspectiva psicanalítica.

A escolha de determinados sujeitos está embasada nos seguintes critérios: primeiro no envolvimento com o contexto educacional, nesse caso, a escola, local onde encontramos vários alunos advindos de diversas realidades e configurações familiares; segundo pelo comprometimento dos professores universitários em causar reflexões e problematizações acerca desse assunto, pois são eles que colaboram na construção de outro profissional que irá atuar nos diversos campos educacionais; e por último, as psicólogas que em sua formação estudam o desenvolvimento, $\mathrm{o}$ comportamento e as relações dos seres humanos em suas diversas faixas etárias.

Nesse seguimento, usamos como instrumento de coleta de dados alguns questionários, todos eles continham duas questões fechadas e uma aberta. A primeira questão estava relacionada com a posição a favor ou contra a adoção por casais do mesmo sexo. A segunda questão estava relacionada com a opinião dos participantes, no que diz respeito ao desenvolvimento da sexualidade da criança inserida num contexto de família homoparental e se a criança recebia alguma influência em sua identidade de gênero e orientação sexual. E a última questão era para que o sujeito pudesse se justificar/expor sua opinião de maneira dissertativa.

Quando em contato com os investigados percebeu-se que nem todos se dispuseram de interesse em participar. Quanto aos acadêmicos, apenas 20 responderam os questionários, sendo que um deles deixou a questão dissertativa em branco, e os outros sete não responderam. Com relação aos professores, apenas 05 responderam, os outros seis não responderam. 
Relativamente as psicólogas, 03 responderam, uma se recusou a participar, outras duas não retornaram os questionários.

Os dados foram transcritos e organizados em um quadro, facilitando assim a compreensão, a relação e a escolha dos momentos mais interessantes tanto das entrevistas quanto dos questionários. Os dados foram selecionados e organizados de maneira que mais atendessem aos objetivos dessa pesquisa. Posto isto, podemos dizer que os entrevistados ficaram conhecidos da seguinte forma: as acadêmicas de A1, A2, A3... e A20; os (as) professores (as) de P1, P2, P3, P4 e P5; as psicólogas de
Psi1, Psi2, Psi3 e Psi4. Na sequência apresentamos os gráficos e pontos que consideramos mais relevantes em relação aos dados.

\section{Apresentação e discussão de dados quantitativos}

A seguir apresentamos os dados mais significativos obtidos por meio dos questionários dos participantes da pesquisa. O gráfico 1 abaixo demonstra a quantidade de acadêmicos, professores e psicólogos que são a favor e contra a adoção por casais homoafetivos, bem como aqueles que não responderam os questionários.

Gráfico 1: Opinião dos participantes sobre adoção por casais homossexuais

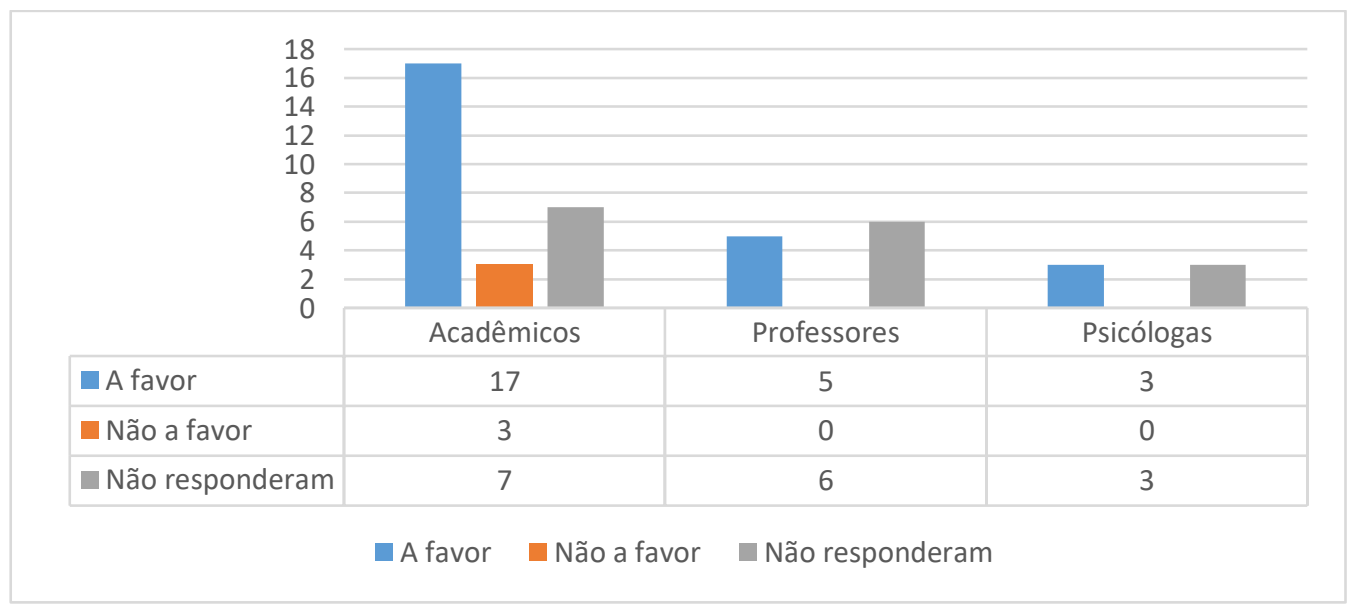

Fonte: Autores (2019). 
Nota-se nesse gráfico que na turma no $8^{\circ}$ semestre do curso de Pedagogia na Universidade Federal do Mato Grosso do Sul, campus de Naviraí, cerca de 62,9\% (17) são a favor da adoção de crianças por casais do mesmo sexo, enquanto apenas $11,1 \%$ (3) não são a favor e $25,9 \%$ (7) não responderam as questões e não retornaram o questionário. Acreditamos que essas últimas não tiveram interesse de participar da pesquisa, pois teriam receio de expor suas opiniões, supostamente, acreditamos que não poderiam dispor de seu tempo para tratar de um assunto não seja relevante na sua visão.

Em relação aos professores dos respectivo curso e campus, $45,4 \%$ (5) são a favor da adoção por pares do mesmo sexo, enquanto 54,5\% (6) preferiram não demonstrar sua opinião, as justificativas recebidas foram por falta de tempo, por estar em eventos acadêmicos, férias e outros ainda, não apresentaram justificativa.

Sobre a opinião das psicólogas notamos de $50 \%$ (3) delas são a favor da adoção por casais do mesmo sexo, enquanto $50 \%$ (3) não se dispuseram a responder, suas justificativas serão dadas a partir do gráfico posterior.

No tocante ao Gráfico 2 é possível notar a quantidade de acadêmicos, professores e psicólogos que acreditam ser ou não prejudicial que a criança seja adotada por um casal do mesmo sexo, além disso, o referido gráfico também aponta a quantidade dos respectivos investigados que não responderam a essa questão. 
Periódico do Núcleo de Estudos e Pesquisas sobre Gênero e Direito

Centro de Ciências Jurídicas - Universidade Federal da Paraíba

V. 9 - $\mathrm{N}^{\circ} 02$ - Ano 2020

ISSN | 2179-7137 | http://periodicos.ufpb.br/ojs2/index.php/ged/index

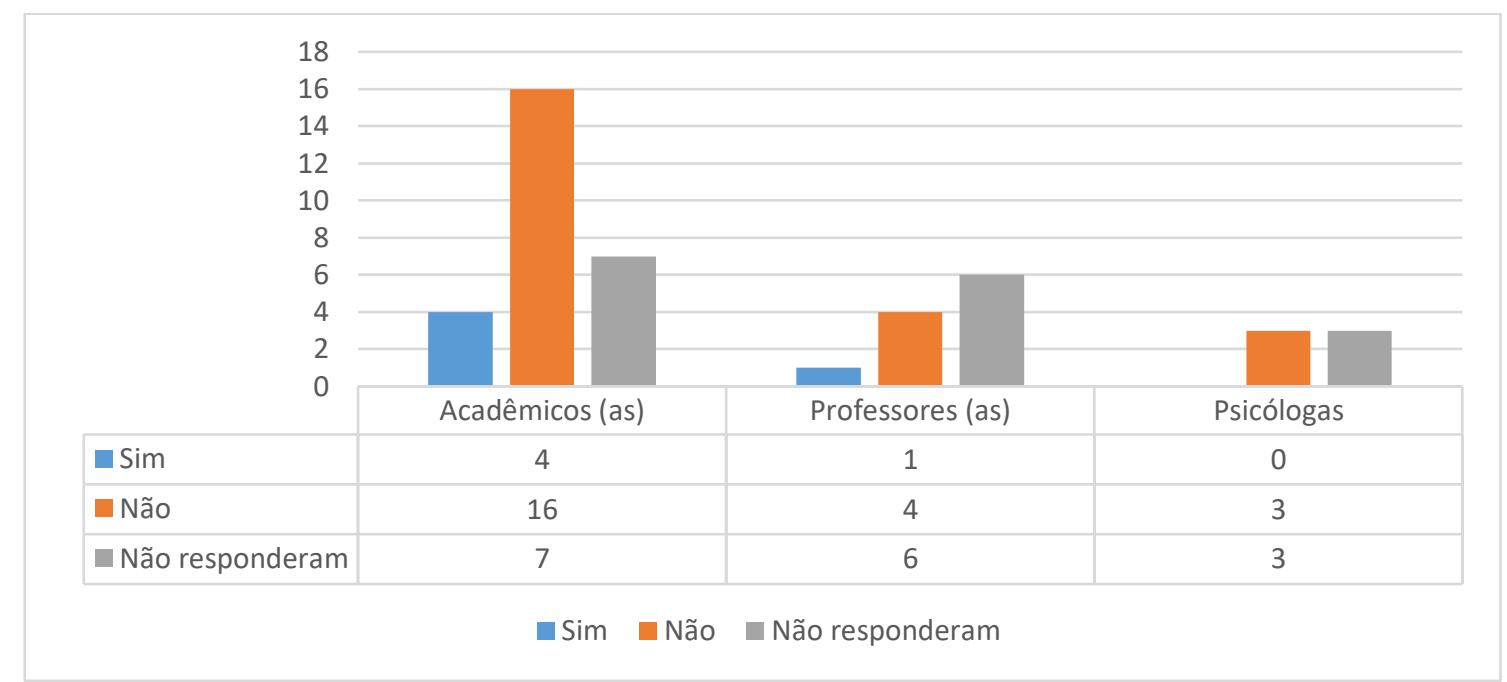

Fonte: Autores (2019). 
Nesse gráfico, percebemos que 59,2\% (16) das acadêmicas acreditam que a criança estar inserida numa família homoparental não prejudica em nada seu desenvolvimento na personalidade ou de identidade sexual. Em contrapartida, 14,8\% (4) acreditam que sim, isso prejudica.

Na segunda categoria, cerca de 36,3\% (4) dos professores acreditam que nada interfere nesse sentido, enquanto $9 \%$ (1) acredita que sim, há uma interferência no desenvolvimento da criança, mas essa interferência não importa, o que importa é que essa criança seja um ser humano aberto as novas realidades.

No que diz respeito a essa questão, notamos que 50\% (3) das psicólogas acreditam que a configuração familiar não interfere em nada para o desenvolvimento da criança, contudo, vale ressaltar que uma das participantes que não estão inclusas no gráfico declinaram sobre o convite, pois ela afirma que, apesar de ser um assunto em pauta nacional, não tem disposto de tempo para estudar sobre o assunto, nesse sentido, podemos afirmar que 16\% (1) das psicólogas não pesquisam sobre o assunto, mesmo sendo relevante como fora afirmado.

\section{Apresentação e discussão dos dados qualitativos}

Quando questionados a respeito do convívio familiar homoparental influenciar o desenvolvimento da personalidade e da sexualidade da criança adotada, percebemos que as estudantes de pedagogia compreendem que a personalidade e sexualidade da criança se desenvolvem de muitas maneiras. Assim, dividimos as respostas em categorias: a primeira é que a criança já nasce assim e o meio social em nada interfere; a segunda é que a personalidade e sexualidade são inatas, mas o meio social contribui para seu desenvolvimento; a terceira é que a personalidade/sexualidade são inerentes, mas depois o sujeito pode escolher o que ser; a quarta é que a criança é influenciada somente pelo meio social; a quinta de que a orientação sexual é uma opção de escolha; a sexta de que a criança precisa dos papéis de gênero para escolher o que vai ser. Essas categorias podem ser confirmadas pelas seguintes falas: “[...] acredito que isso já é inato da criança.” (A1), “[...] já nascemos e vamos com o tempo edificando o que já temos [...]” (A6), “[...] cada pessoa nasce com um caráter, ou seja, no decorrer de sua infância pode optar por ser 
hétero, bi ou homo, e isso não depende de seus pais [...]." (A3), "Acredito que a criança é influenciada pelo meio social." (A9), “A opção sexual não altera a personalidade da criança." (A12) e "[...] a crianças constrói sua identidade e por experiência, convívio e sendo do mesmo sexo quais as escolhas ela pode ter [...].” (A13).

Notamos que essas compreensões acerca do desenvolvimento da personalidade são coerentes em alguns aspectos e vão de encontro com aquilo que Papalia e Feldman (2013) afirmavam a respeito da existência de diversas abordagens que explicam o desenvolvimento do ser humano e a definição de seu gênero. Contudo, nem todas essas categorias se enquadram dentro das abordagens citadas pelos autores, como por exemplo, algumas acadêmicas ainda entendem a orientação sexual como uma opção, como uma escolha. Desse modo, lembramos que a orientação sexual é algo involuntário, automático, não é uma decisão dos sujeitos (SÃO PAULO, 2014).

Destacamos ainda nesse tópico a opinião religiosa quanto a adoção e influência que o casa homossexual exerceria na orientação sexual da criança. Observamos que as opiniões religiosas estão embasadas em princípios e modelos cristãos, e muitas delas afirmam não desrespeitar as escolhas de ninguém. Tal questão pode ser confirmada pela seguinte escrita “Ainda tenho princípios cristãos e acredito na instituição familiar no modelo cristão. Claro que não desrespeito a escolha sexual de ninguém, respeito o ser humano igualmente." (A5).

Tal apontamento anterior também confirma o que as palavras de Victória Clarke (2001) dizem a respeito dos argumentos de base religiosa, usados na maioria das vezes para mascarar algumas questões que geram preconceito e não aceitação das famílias homoparentais.

Com relação aos professores universitários foram possíveis constatar opiniões desprovidas de estereótipos, muitas delas vão de encontros com as ideias citadas acima, sobre as diversas abordagens do desenvolvimento da personalidade e de gênero. É possível destacar em suas falas os seguintes: um paradoxo em relação família homoparental e heterossexual; a pressão da sociedade preconceituosa pode influenciar o desenvolvimento da personalidade e a criação; as relações com essa nova família não vão interferir, mas contribuir para que a criança compreenda os novos arranjos familiares. 
Confirmamos esses dados com as seguintes escritas: “[...] A hipótese de que casais homoafetivos levam à homossexualidade dos filhos é falsa, haja vista existirem pessoas homossexuais advindas de pais ditos heterossexuais [...]” (P02), “[...] que a pressão da sociedade pode influenciar sim, já que vivemos numa sociedade preconceituosa [...]" (P03) e "[...] as relações sociais vivenciadas por essa criança vão possibilitar ela perceber que existem outros tipos de família para além da família constituída por um pai e uma mãe”.

Essas observações nos levam a concluir que os novos arranjos familiares contribuem para a formação de um ser humano mais compreensível e aberto para a diversidade de existente em nossa sociedade. Quando vamos observar as opiniões das psicólogas percebemos as seguintes respostas:

A criança em desenvolvimento é fruto de diversas influências: as ambientais (sociais, culturais), as de aleatoriedade dos acontecimentos e das potencialidades inatas herdadas. Deste modo, não é coerente classificar a questão da identidade sexual por apenas um prisma.

Na medida em que a criança amadurece neurologicamente vai desenvolvendo a capacidade do pensamento, da linguagem e da percepção de si mesma. A criança emocionalmente saudável - e isso não depende do fato de crescer em um lar homo ou heterossexual - conseguirá construir sentimentos de autoestima, auto respeito que proporcionarão crenças positivas, como: "Eu posso ser amada, eu tenho valor". (PSi1)

A personalidade de uma criança é moldada a partir de suas vivencias e experiências uma vez que seja adotada por pessoas saudáveis que cuidem de forma responsável da mesma, explicando e orientando acerca da situação vivenciada (nova configuração de família e pais) não acredito que irá ocorrer algum prejuízo na formação de sua personalidade devido a adoção por casal homossexual. (PSi3)

Geralmente essas crianças vão ser motivos de chacota e brincadeiras maldosas de alguns colegas, mas certamente vai estar fortalecido e saberá tirar de letra tudo isso. E até ensinar os colegas que devem respeitar as pessoas, independentemente do que sejam, façam ou pensem em sua intimidade ou fora dela. Mas se tal situação chegar ao extremo, os pais devem tomar providencias para proteger o filho e exigir respeito. Nem que seja preciso aplicar a lei. Crianças criadas por pais e mães homossexuais, não significa que terão uma orientação sexual também. Se não, os pais de pessoas homossexuais, não seriam heterossexuais, não é mesmo? (PSi4).

Nesse sentido, é evidente que na opinião das psicólogas há vários fatores que participam da construção da identidade de uma criança e que a família seria um ambiente social pouco relevante para interferir na orientação sexual da criança, visto que, a 
orientação é tida como algo inerente, afirma Papalia e Feldman (2013) e a Coordenação de Políticas para a Diversidade Sexual (São Paulo, 2014).

\section{Considerações finais}

Consideramos que com base nos percursos históricos acerca da homossexualidade podemos compreender que ela não é uma invenção da pósmodernidade, mas uma realidade que vendo sendo vivida e perpetuada desde a antiguidade. Nesse sentido, entendemos que a prática homossexual a princípio tinha normas e preceitos pedagógicos e que se tal fosse realizada fora dos padrões era tida como imoral, ilícita e desavergonhada, o que nos leva a crer que esse seria um dos motivos pelo qual o preconceito contra as pessoas de orientação homossexual tem se mantido até a atualidade.

Quando tratamos da questão da sexualidade humana, compreendemos que muitos autores afirmam que a mesma é formada por uma combinação de muitos fatores biológicos, psicológicos e sociais, e que ainda é composta por outros três elementos, o sexo biológico, que compreende o aparelho genital que o indivíduo nasce, a orientação sexual, que se refere a atração afetiva/sexual por outra pessoa (podendo ser heterossexual, homossexual e bissexual) e a identidade de gênero, que envolve a percepção que o indivíduo tem de si mesmo em relação ao seu gênero (masculino ou feminino).

Em relação às novas configurações familiares, cremos que o mais relevante a se destacar seja que no Estado brasileiro as leis com relação ao reconhecimento da união estável em casamento civil tenha sido o grande passo, entretanto, o impasse a ser enfrentado é o reconhecimento legal da existência de famílias homoparentais como novos arranjos familiares, ou seja, reconhecer como instituição família aquelas formadas por pessoas do mesmo sexo e que adotam crianças.

No tocante a problemática desse trabalho que era relacionado ao seguinte questionamento: Será que o modelo de família homoparental pode interferir no desenvolvimento da sexualidade de uma criança adotada? Mediante o desenvolvimento da pesquisa bibliográfica e das entrevistas realizadas com as alunas do $8^{\circ}$ semestre do curso de Pedagogia, com os professores do respectivo curso e com as psicólogas, 
percebemos que a família, seja ela de qualquer configuração, é um meio que pouco vai interferir no desenvolvimento da sexualidade das crianças que são adotadas, principalmente, daquelas adotadas por casais homossexuais. Portanto, os argumentos levantados contra as famílias homoparentais em relação a adoção de crianças tornam-se esclarecidos e desmistificados.

Com referência ao objetivo desse trabalho que era o de compreender como se dá o desenvolvimento sexual de crianças adotadas/ou que convivem como famílias homoparentais, verificou-se que o mesmo ocorre normalmente e não há nenhuma preocupação especial com relação as saúde física, psicológica, de adaptação, com confusão de gênero ou funcionamento sexual, muito pelo contrário, a convivência com novos arranjos familiares faz com que as crianças crescem compreendendo e respeitando as diferenças e diversidades existentes.

Por fim, notamos que grande parte das categorias investigadas demonstra estar abertas as mudanças que vem ocorrendo na sociedade, bem como compreender que as novas configurações familiares não influenciam o desenvolvimento da criança, rebatendo a ideia do senso comum. Nesse aspecto, é de suma importância que na nossa sociedade brasileira desenvolva mais estudos sobre essas questões e que chegue ao conhecimento dos cidadãos brasileiros, pois acreditamos que quando compreendemos uma realidade podemos rever conceitos e padrões internalizados e desconstruí-los, buscando eximir preconceitos, como é o caso da família homoparental interferir na identidade sexual de uma criança.

\section{Referências bibliográficas}

SÃO PAULO. Governo do Estado. Secretaria da Justiça e da Defesa da Cidadania. Coordenação de Políticas para a Diversidade Sexual. Diversidade sexual e cidadania LGBT. São Paulo : SJDC/SP, 2014. Disponível em: http://www.recursoshumanos.sp.gov.br/lgbt/cartilha_diversidade.pdf. Acesso em 25 nov 2019. 
BRASIL. Lei 8.069, de 13 de Julho de 1990. Estatuto da Criança e do Adolescente. Brasília: Ministério da Justiça, 1990. Disponível em: http://www.febem.sp.gov.br/files/pdf/eca.pdf. Acesso em: 25 nov. 2019.

BRASIL. Conselho Nacional de Justiça. Resolução No 175 de 14/05/2013. Dispõe sobre a habilitação, celebração de casamento civil, ou de conversão de união estável em casamento, entre pessoas de mesmo sexo. Disponível em: http://www.cnj.jus.br/files/atos_administrativos/resoluo-n175-14-05-2013presidncia.pdf. Acesso em: $10 \mathrm{dez} 2019$.

CLARKE, Victória. What about the children? Arguments against lesbian and gay parenting. Women's Studies International Forum, n. 24, p. 555-570, 2001. Disponível em: https://www.sciencedirect.com/science/article/abs/pii/S0277539501001935. Acesso em 15 dez 2019.

COSTA, Pedro Alexandre et al. Atitudes da população portuguesa em relação à homoparentalidade. Psicol. Reflex. Crit., Porto Alegre, v. 26, n. 4, p. 790-798, dez. 2013. Disponível em: http://www.scielo.br/scielo.php?script=sci_arttext\&pid=S010279722013000400020\&lng=pt\&nrm=iso. Acesso em: 25 nov. 2019.

DIAS, Maria Berenice. Adoção homoafetiva. Casa da Maitê. 2004. Disponível em: http://berenicedias.com.br/uploads/6_-_ado\%E7\%E3o_homoafetiva.pdf. Acesso 25 out. 2019.

GATO, Jorge; FONTAINE, Anne Marie. Impacto da orientação sexual e do género na parentalidade: Uma revisão dos estudos empíricos com famílias homoparentais. Ex aequo, Vila Franca de Xira, n. 23, p. 83-96, 2011. Disponível em: http://www.scielo.mec.pt/scielo.php?script=sci_arttext\&pid=S087455602011000100008\&lng=pt\&nrm=iso. Acesso em: 25 nov. 2019. 
GIL, Antonio Carlos. Métodos e técnicas de pesquisa social. Disponível em: 197.249.65.74:8080/biblioteca/handle/123456789/707. Acesso em 12 nov. 2017.

LAKATOS, Eva Maria; MARCONI, Marina de Andrade. Metodologia Científica. 6. ed. São Paulo: Atlas, 2011.

PAPALIA, Diane E.; FELDMAN, Ruth Duskin. Desenvolvimento Humano. $12^{\mathrm{a}}$ ed. Porto Alegre. 2013.

PASSOS, Maria Consuelo. Homoparentalidade: Uma entre outras formas de ser família. Psic. Clin., Rio de Janeiro, v. 17, n. 2, p.3 -40, 2005. Disponível em: http://www.scielo.br/pdf/\%0D/pc/v17n2/v17n2a03.pdf. Acesso em: 25 out. 2019.

PEREIRA, Diogo Fagundes. Homossexualidade em cena: Da naturalidade ao preconceito revisitando a produção científica nacional. Itinerarius Reflectionis, [S.l.], v. 13, n. 2, p. 01 - 19, ago. 2017. Disponível em: https://www.revistas.ufg.br/rir/article/view/41309. Acesso em: 25 nov. 2019 